\title{
DISCURSOS DE ENFERMEIROS SOBRE HUMANIZAÇÃO NA UNIDADE DE TERAPIA INTENSIVA
}

\author{
Speechs of nurses about humanization in the intensive care unit \\ Discursos de enfermeros sobre la humanización en la unidad de terapia intensiva
}

\section{RESUMO}

Pesquisa qualitativa, cujo objetivo foi identificar elementos da prática dos enfermeiros de terapia intensiva que dificultam a implementação da humanização da assistência, analisando-os à luz da Política Nacional de Humanização. Realizaram-se entrevista semiestruturada com 22 enfermeiros de uma unidade de terapia intensiva e análise temática de conteúdo. 0 usuário, a família e a equipe integram a prática cotidiana de cuidados, mas os dispositivos da humanização contidos na Política, como visita aberta, ambiência, acolhimento, interação com a equipe multiprofissional, oficinas e grupos de trabalho, não são efetivamente implementados para eles. Há dificuldades que indicam necessidade de investimentos na formação e na gestão institucional e do cuidado, de modo que a política de humanização seja efetivamente implantada na unidade de terapia intensiva.

Palavras-chave: Unidades de terapia intensiva. Enfermagem. Cuidados de enfermagem. Humanização da assistência.

\begin{abstract}
Qualitative research whose aim was to identify elements of the practice of intensive care nurses that difficult the implementation of the humanization of care, analyzing them according to the National Policy of Humanization. It was carried out semistructured interviews with twenty-two nurses from an intensive care unit and theme analysis of content. The user, family and the team integrate everyday practice of care, but the rules of the Humanization contained in Policy as visit open, ambience, welcome, interaction with the multidisciplinary team, workshops and group of work aren't effectively implemented. There are difficulties that indicate the need to invest in training and institutional management, and in care, so that the humanization policy can be effectively implemented in the intensive care unit.
\end{abstract}

Keywords: Intensive Care Units. Nursing. Nursing care. Humanization of assistance

\section{Resumen}

Investigación cualitativa, cuyo objetivo fue identificar elementos de la práctica de los enfermeros de terapia intensiva que dificultan la implementación de la humanización del cuidado, analizándolos a la luz de la Política Nacional de Humanización. Se realizó entrevista semi-estructurada con 22 enfermeros de una unidad de terapia intensiva y análisis temático de contenido. El usuario, la familia y el equipo integran la práctica cotidiana de atención, pero los dispositivos de la humanización contenidos en la Política como visita abierta, ambiente, acogimiento, interacción con el equipo multiprofesional, oficinas y grupos de trabajo no son efectivamente implementados junto a estos. Hay dificultades que indican necesidad de inversiones en la formación y en la gestión institucional y de la atención, de manera que la política de humanización sea efectivamente implantada en la Unidad de Terapia Intensiva.

Palabras claves: Unidades de Terapia Intensiva. Enfermería. Atencion de Enfermería. Humanización de la Atención.

\footnotetext{
${ }^{1}$ Enfermeira. Aluna do Curso de Mestrado do Programa de Pós-Graduação em Enfermagem da Escola de Enfermagem Anna Nery, da Universidade Federal do Rio de Janeiro (EEAN-UFRJ). Rio de Janeiro - RJ. Brasil. E-mail: fernanda23_dasilva@yahoo.com.br; ²Enfermeira. Aluna do Curso de Mestrado do Programa de Pós-Graduação em Enfermagem da Escola de Enfermagem Anna Nery, da Universidade Federal do Rio de Janeiro (EEAN-UFRJ). Membro do Núcleo de Pesquisa de Fundamentos do Cuidado de Enfermagem (Nuclearte). Rio de Janeiro - RJ. Brasil. E-mail: zizimoraes@hotmail.com; ${ }^{3}$ Doutor em Enfermagem, Membro do Nuclearte. Rio de Janeiro - RJ. Brasil. Email: rafaenfer@yahoo.com.br; ${ }^{4}$ Doutora em Enfermagem. Professora Titular do Departamento de Enfermagem Fundamental da EEAN-UFRJ. Membro do Nuclearte. Pesquisadora 1D do CNPq. Rio de Janeiro - RJ. Brasil. Email:marciadeaf@ibest.com.br
} 


\section{INTRODUÇÃO}

As unidades de terapia intensiva (UTI) tiveram origem na década de 50, com a evolução da tecnologia na área da saúde. Essas unidades surgiram da necessidade de atender a pacientes críticos, cuja gravidade gera tensão tanto nos usuários quanto nos membros da equipe de saúde que trabalham neste setor. Como o cenário da terapia intensiva (TI) é repleto de tecnologias, surgem sempre preocupações sobre a humanização. Quando vêm à tona as discussões sobre práticas de desumanização na assistência de enfermagem, quase que em associação, em co-ocorrência, surgem as alusões ao desenvolvimento das tecnologias ${ }^{1-3}$.

Um dos elementos envolvidos neste debate acerca da relação entre a tecnologia e a desumanização do cuidado ar ticula-se às situações de assistência em que, à primeira vista, ocorre predominância da máquina e dos dados objetivos que ela mostra, em detrimento de outros procedimentos mais ligados ao cuidado direto aos usuários e da subjetividade implicada na relação entre humanos. Deste modo, a interação entre o sujeito que recebe 0 cuidado e o profissional seria considerada eventualmente suplementar, dispensável ou até mesmo ausente. Não obstante, defende-se a ideia de que os recursos tecnológicos são importantes, porém não mais relevantes do que a essência humana. Logo, a equipe de enfermagem que atua nestas unidades não deve esquecer que a máquina não substituirá a essência humana ${ }^{4-5}$.

A equipe de enfermagem que atua na $\mathrm{TI}$ costuma pensar na tecnologia como "máquinas que parecem ser a alma, a espinha dorsal das unidades" ":157. Isso se justifica principalmente pelo fato de as UTI possuírem uma especificidade própria, diferente das demais áreas hospitalares, já que os recursos tecnológicos exigem da equipe de enfermagem um estilo de cuidar peculiar em relação às outras unidades. Ressalta-se, contudo, que tal estilo deve-se fundamentar no atendimento às necessidades humanas, a partir da tecnologia, mas também sob a ótica dos outros fatores ambientais que poderão interferir na restauração da saúde. Neste sentido, é necessário refletir em que medida a tecnologia se constitui no verdadeiro problema que se encontra nas UTI. Isso porque se observa, em diversas circunstâncias, aspectos que denotam a ausência do cuidado de enfermagem e que acabam desviando as atenções para a tecnologia como principal responsável ${ }^{5}$; tecnologia aqui entendida como o maquinário ${ }^{6}$ próprio a este setor.

Situações ditas desumanizantes, como comentários inoportunos, barulhos constantes, falta de privacidade do usuário e a utilização de rótulos e apelidos para se referir a ele, ocorrem em muitos setores, não sendo a tecnologia o único foco de desumanização da assistência de enfermagem ao usuário em cenários caracterizados pelo seu uso intenso. como, por exemplo, os de terapia intensiva ${ }^{7}$. Nesta perspectiva, é necessário ampliar a discussão sobre a humanização na TI, abarcando outras dimensões que não simplesmente a tecnológica.

Em 2004, o Ministério da Saúde do Brasil criou a Política Nacional de Humanização (PNH), tendo a humanização como eixo norteador das práticas de atenção e gestão da saúde em todas as instâncias do Sistema Único de Saúde (SUS). Na PNH há participação com autonomia e responsabilização de todos os sujeitos atuantes nos processos de saúde: gestores, trabalhadores e usuários ${ }^{8-9}$.

No caso das UTI, a PNH engloba a visita aberta; o mecanismo de recepção com acolhimento dos usuários; o recurso de escuta para a população e os trabalhadores; a garantia de continuidade da assistência; a definição de protocolos clínicos, eliminando as intervenções desnecessárias e respeitando as diferenças e as necessidades do sujeito; atendimento multiprofissional à família com horário pactuado entre ambos ${ }^{1}$.

A humanização no âmbito da enfermagem suscita um debate acerca dos elementos envolvidos no cuidado de dimensão tanto técnica quanto expressiva. Sob esta ótica, e tendo em vista a problemática delineada voltada para uma polarização do diálogo nesta área sobre a humanização na TI com foco na tecnologia, o objeto desta pesquisa é a humanização neste cenário de cuidado.

Objetiva-se identificar os elementos da prática dos enfermeiros de UTI que dificultam a implementação da humanização da assistência, analisando-a à luz da PNH. A relevância deste estudo reside no argumento de que humanizar a assistência na UTI está em relacionar o conhecimento à responsabilidade, à ética, à sensibilidade destinada aos usuários e suas famílias. Destaca-se, assim, que a humanização da UTI é um dever moral, ético e legal dos profissionais, compreendendo múltiplas dimensões'.

Portanto, este estudo contribui para melhor entender as questões ligadas à humanização, tomando por base as políticas atuais de saúde, possibilitando, principalmente aos profissionais da área da enfermagem, um aprofundamento do debate atual da temática, que lhe forneça subsídios à prática do cuidado em uma perspectiva humanizadora, considerando as características que se processam na terapia intensiva.

\section{METODOLOGIA}

Pesquisa de campo, qualitativa, do tipo descritiva e exploratória. Explorou-se o que pensam e fazem os enfermeiros na TI, em articulação com os preceitos da PNH, a partir da produção de discursos sobre suas práticas.

0 campo foi um centro de terapia intensiva (CTI) de uma instituição pública do município do Rio de Janeiro, e os sujeitos foram 22 enfermeiros que atenderam aos seguintes critérios de inclusão: atuar na assistência ao usuário no CTI durante o período de realização deste estudo, que foi de novembro de 2010 a maio de 2011, além de aceitar participar 
da pesquisa. 0 não atendimento a estes critérios implicou na exclusão dos sujeitos.

A técnica de produção de dados foi a entrevista semiestruturada, que explorou os sentidos do cuidado na terapia intensiva e como se dão as práticas dos enfermeiros neste cenário em face das tecnologias (maquinário) existentes. Os registros das entrevistas foram feitos em equipamento eletrônico do tipo mp3, cujos conteúdos foram transcritos na íntegra. Ao corpus de dados aplicou-se a análise de conteúdo temática ${ }^{10}$, a qual gerou três categorias, cada qual organizada em torno de um dos elementos implicados na prática cotidiana de cuidados na TI, quais sejam: os usuários, a família e a equipe. Tais elementos, reunidos, deram sentido aos discursos dos sujeitos sobre o objeto em tela articulando-se à questão foco da humanização.

A pesquisa foi aprovada pelo Comitê de Ética de um Hospital Geral Público do Rio de Janeiro, lócus da pesquisa, sob número de protocolo 35/10. Os sujeitos assinaram o Termo de Consentimento Livre e Esclarecido, mantendo-se o anonimato por meio da identificação numérica dos enfermeiros, com base na ordem sequencial em que se realizou a entrevista.

\section{RESULTADOS E DISCUSSÃO}

\section{A subjetividade do usuário na unidade de terapia intensiva}

Um dos aspectos que emerge no contexto da prática de cuidar dos enfermeiros na TI, na interface com a humanização, é a relação que tais profissionais mantêm com os usuários nas suas ações de cuidar. Neste sentido, o cotidiano de assistir traz demarcada a dinâmica que o enfermeiro confere ao seu trabalho diário, bem como as prioridades que estabelece no âmbito do seu fazer. Ao contrastar o usuário capaz de interagir e a prática de cuidar dos enfermeiros, aparecem alguns contornos desta assistência, os quais revelam um sentimento de isolamento vivenciado pelo usuário. Em razão da importância atribuída às atividades e da situação clínica de outros usuários, alguns são postos em segundo plano.

Épara ser sincera mesmo, vou ser sincera, porque tem paciente que é chato. Quando o paciente é legal, paciente legal não é aquele que aceita tudo não, é paciente que é bacana, que fala que está sentindo isso e tal. Tem uns pacientes chatos mesmo. Quando é chato, o pessoal vai deixar lá, vai ficar confinado, o pessoal nem vai aparecer, porque qualquer coisinha é dor, dor, dor, mas às vezes nem é dor é mais atenção. Tem uns que acham que é enfermagem particular. Você tem $n$ pacientes, acham que tem que estar do lado'fica comigo, vamos conversar', acha que a gente tem que ficar ali parada para conversar. Tem paciente que é chato, tem paciente legal, tem paciente que fica naquele martela, martela, martela (Enf. 1).
Ele vai interagir com o paciente, ele não vai conseguir porque vão chamar, tem telefone para atender, tem paciente para tomografia, é muito difícil, o paciente vai se sentir só mesmo. 0 enfermeiro não consegue achar tempo para essas coisas, aí daqui a pouco o cara vai almoçar, volta uma hora, um corre-corre danado, como você vai parar para sentar com o paciente, 'está tudo bem com o senhor, como o senhor está?', se daqui a pouco estão chamando, é muito difícil essa interação (Enf. 3).

O paciente se sente só, é aquela questão, a gente não tem essa manha de ficar indo no leito, independente do paciente estar precisando da gente ou não, ficar ouvindo, enfermeiro de CTI, eu não tenho, é um erro talvez, mas eu tenho bastante coisa para fazer porque a gente não está ali disponível o tempo inteiro, e a pessoa não tem ninguém para conversar. Por isso que é o momento da pessoa ir embora, porque a gente não tem condições de oferecer aquele bem-estar de ficar ali batendo papo (Enf. 6).

Evidencia-se a dificuldade da interação com o usuário, através da qual seria possível captar informações objetivando atender às suas necessidades. A interação é demandada por ele, mas pouco atendida pelo enfermeiro. Uma das características que se observa no corpus de análise pauta-se no argumento de que, no CTI, pelas peculiaridades de ser um setor voltado a pessoas criticamente enfermas, portadores de condições complexas, a prioridade são os doentes mais graves e os dados objetivos a eles relacionados, fornecidos pelo maquinário, o que faz enaltecer a tecnologia. Consequentemente se desvalorizam as situações que envolvam uma interação mais aprofundada com o usuário, de onde possivelmente se teria maiores condições de propiciar atenção às suas histórias, às informações fornecidas por ele que possam subsidiar um cuidado mais individual, que atenda a outras necessidades não identificadas pelo exame físico ou clinico.

Esse que está mais acordado é o menos observado, porque a gente gosta de pacientes mais sedados, mais graves, de uma forma geral, e quando a gente vainesse paciente, a gente acaba pescando apenas o que ele tem a informar, em relação de imediato ali ao que a gente está vendo. A gente acaba não conversando além, sobre a família, sobre alguma coisa que pode trazer dados também para o nosso diagnóstico, por vários motivos, porque ele acaba sendo o último mesmo a ser visto, porque a gente tem, prioriza os outros, e aí como ele está bem clinicamente, eu acabo indo para outras coisas a 
fazer, volto para burocracia, que eu tenho quinhentos milhões de coisas para fazer, não dá para ficar ali à beira do leito, ouvindo todas as histórias que ele tem para contar (Enf. 6).

Agora que éfato que as pessoas lidam com isso de maneiras diferentes, é, tem enfermeiro que vai estar muito mais próximo, e tem enfermeiro que não vai estar, eu tenho enfermeiro que, na hora de fazer a escala, vaipedir para não ser escalado com paciente que esteja lúcido e orientado. Agora, a questão objetiva, a questão palpável é importante no CTI, isso é o diferencial no CTI e vai continuar sendo para sempre, o subjetivo no CTI sempre vai ser tratado, como algo, não digo em segundo plano, mas algo secundário, secundário àquilo que é o elemento principal, que é o cuidado tecnológico, cuidado direcionado a evidências claras concretas, até porque a nossa formação em terapia intensiva é muito voltada para isso (Enf.15).

Outro fato a se problematizar é o respeito à individualidade do usuário. Sob esta perspectiva, o relato de oito depoentes ilustra a ocorrência de circunstâncias nas quais se percebe indícios de como este princípio fundamental é abordado: a exposição do corpo do usuário, barulhos excessivos e falta de consideração às suas vontades e desejos.

Eu acho que o que deve incomodar é o barulho, $O$ nosso barulho, mas acho que o que deve incomodar é a exposição. Acho que a enfermagem não expõe muito não, mas como não tem só a gente aqui, várias vezes eu pego um paciente exposto, exposto, nu (Enf. 4).

Eu acho que eles se sentem muito mal nessa questão da informação, quando ele está lúcido ele é mal informado, ou não é informado sobre o porquê de estar no CTI, para que está no CTI, quanto tempo ele vai ficar. A manipulação também, eu vejo que a gente expõe demais o cliente (Enf. 10).

O paciente entubado um tempão, aquele despertar ruim, e ele sempre agoniado, e quando ele foi extubado: "Poxa, vocês cobriam meu pé, enfiavam o cobertor tampando e eu só durmo com o pé descoberto!", mas assim, tinha que ter feito uma coleta de dados com a família, o que ele gosta, 0 que ele não gosta, porque era uma coisa que incomodava muito a ele, uma coisa para a gente muito boba, deixava igual um envelopinho, porque estava lindo, o paciente todo esticadinho e ele não gostava (Enf.19).
Tal configuração da prática dos enfermeiros favorece a sensação de solidão dos usuários, embora haja profissionais presentes. Observa-se que a demanda interativa dos usuários assume um tom negativo no discurso dos enfermeiros. A metodologia de obtenção de dados pela anamnese pauta-se na interação clínica, e como grande parte dos enfermeiros considera que as tecnologias aportam todas as informações de que precisam, dispensam a interação considerando-a mais uma ocupação.

Contudo, entende-se que os usuários enfrentam um desgaste emocional por presenciarem situações críticas, somando-se ao constante barulho dos aparelhos e conversas dos profissionais, indicando, então, a necessidade de cuidado pelo enfermeiro também nesta esfera. Um ponto interessante nesta discussão refere-se aos sentidos construídos pelos usuários. Em pesquisa que buscou identificar as representações sociais dos enfermeiros sobre a tecnologia no ambiente da TI, evidenciou-se que a UTI se configura como um setor desconhecido pelos usuários, criando dessa forma um estigma sobre ela. Quando um usuário entra na UTI, acredita que esteja entre a vida e a morte, e este cenário gera insegurança e medo, já que o senso comum o entende como um lugar sinônimo de morte $^{11-12}$.

A percepção insatisfatória do paciente internado na UTI está relacionada com os momentos de dúvida quanto à vida e a morte, impotência e dependência, e a percepção de satisfação marca o paciente quando ele tem certeza da vida, da sua continuidade. Observa-se estudos que destacam que a vivência de situações críticas nesse setor pode ser favorecida pela atenção e a dedicação da equipe de saúde, sua demonstração de carinho e apoio emocional ${ }^{11}$. A presença da equipe, o preparo dos profissionais, contribuem para que os usuários possuam uma percepção satisfatória da UTI, sobretudo no que tange à humanização ${ }^{11}$.

Para o usuário, a equipe de saúde representa o eixo de ligação com a vida fora do ambiente de terapia intensiva. Neste sentido, reforça-se a importância dela em se apresentar, explicar os procedimentos, conversar com o usuário, interagir sempre com ele, em especial, a equipe de enfermagem, que presta cuidados integrais. As diversas técnicas e procedimentos na UTI devem ser entendidos como uma vertente que facilita o processo de interação entre a equipe de enfermagem e o usuário internado nesse setor ${ }^{11}$.

Entretanto, existe uma corrente de estudiosos da enfermagem que sinaliza para a existência de uma desvalorização destes aspectos expressivos do cuidado de enfermagem neste setor $^{2,12}$. Esta afirmação fica clara quando se acessam alguns estudos teórico-reflexivos realizados por enfermeiras. Em um desses, refere-se que o relacionamento da equipe de enfermagem com o usuário se resume aos momentos que envolvem os cuidados como o banho no leito, a aspiração endotraqueal, a realização de curativos, a mudança de decúbito, 
cuidados técnico-procedimentais mais realizados na UTI. Acredita-se que o envolvimento da equipe de enfermagem com o usuário e seu familiar ainda esteja longe do que se idealiza².

Tomando como referência o exposto, releva-se a compreensão da vivência subjetiva do usuário hospitalizado neste cenário, através de uma atitude do profissional de saúde de característica acolhedora, empática e baseada no diálogo. A humanização segundo a PNH supõe troca de saberes, diálogo entre os profissionais e modos de trabalhar em equipe ${ }^{9}$. A percepção da equipe de enfermagem neste ambiente de TI deve ampliar-se ao usuário e seu familiar. Logo, a humanização da assistência nas UTI deve perpassar os discursos dos profissionais de enfermagem que cuidam neste setor, pois todas as ações que expressam o cuidado de enfermagem necessitam de ser humanizadas ${ }^{14}$.

Isso pensado sob a ótica da PNH remete a importância de se ter um ambiente acolhedor na TI. A PNH possui como uma das estratégias a ambiência na saúde, que se refere ao tratamento dado ao espaço físico, entendido como espaço de relações entre as pessoas, profissionais e os usuários, devendo propiciar atenção acolhedora, resolutiva e humana. Logo é um espaço que visa à privacidade e confor to tanto dos usuários como dos profissionais de saúde ${ }^{9}$. Essa dimensão pode ser utilizada nas UTI, favorecendo assim um atendimento de qualidade e humanizado aos usuários internados.

\section{A família como sujeito do cuidado na UTI}

A análise dos dados evidenciou uma tendência majoritária no corpus direcionando ao entendimento de que pensar a humanização na TI remete também a compreender 0 cuidado e a atenção que são dados pelo enfermeiro no âmbito das suas ações profissionais à família do paciente crítico. Verificase que neste ambiente há uma preocupação exacerbada do enfermeiro com todos os afazeres que tem a cumprir, mormente àqueles de cunho burocrático, bem como com as informações estritamente de base clínica, relativas ao usuário, e, neste sentido, a família e todas as dimensões implicadas nela parecem não fazer parte dos cuidados prioritários dos profissionais.

Chega na parte da tarde, no momento das visitas, que também é importante de a gente conversar, não só o médico conversar com a família, mas a gente também da enfermagem, a gente acaba deixando isso um pouco de lado, ver o que a família sente para gente poder ajudar também, esse é o momento que a gente senta para poder escrever porque tem que registrar tudo, para poder receber farmácia, fazendo anotação em livro (Enf. 4).

Fica concentrado no posto e os familiares ficam no leito, assim, raros os enfermeiros que descem para conversar, conversar com esses familiares, para interagir e tal (Enf. 18).
Realmente, tem muitas enfermeiras que não têm paciência, e quando chega a hora da visita ela até prefere sair daquele espaço, sumir, para não ter que falar com o acompanhante ali. 0 paciente e 0 acompanhante, por ter toda uma tecnologia envolvida, são carentes. Se você for andar por aí, com certeza as pessoas estão muito frias (Enf. 17).

Além disso, a infraestrutura do cuidado à família também não se mostra adequada, já que não há espaço reservado para este atendimento, nem os profissionais necessários a uma abordagem de qualidade. Isto contribui para a não valorização do familiar como sujeito do cuidado que se articula à assistência do usuário no CTI.

Eu acho que falta aqui uma salinha, acolhimento para o familiar ser recebido, a gente tem ali uma sala onde ficam os prontuários, os médicos prescrevendo, onde é feito o round, mas a gente não tem uma salinha para receber o familiar ali. Essa salinha, acho que seria legal para poder estar conversando com essas familias. Já trabalhei em outra terapia intensiva que tinha essa salinha, e a gente recebia o familiar. Poucas vezes eu consegui, poucas vezes eu passei para conversar com a familia, às vezes um dado que eu observei ou então que a família me passa, ele tem costume de fazer isso (Enf. 4).

[0 psicólogo]É um profissional que a gente não tem no serviço, acho que para o paciente acordado estar com alguém que possa tentar pelo menos fazer esse contraponto com ele é melhor. Por mais que eu tenha tido psicologia na minha formação, eu não sou psicóloga, por mais que faça o cuidado, o apoio psicológico a esse paciente, em algum momento, talvez ele precise de outro profissional (Enf. 5).

A categoria em tela descreve de que maneira a relação existente entre assistência à família do usuário internado na Tl e a questão do foco da humanização se processa nas práticas de cuidar do enfermeiro, revelando as dificuldades de comunicação dos profissionais em tal realidade. Esta discussão acerca da humanização abarcando a dimensão da família tem respaldo em outras pesquisas. Uma delas estudou a humanização do atendimento no âmbito da medicina intensiva, com 100 familiares de usuários de UTI, e avaliou a assistência às famílias. Nos resultados, um total de $96 \%$ considerou a qualidade da equipe médica como ótima ou boa; no entanto, $15 \%$ declararam estar insatisfeitos com as informações médicas $^{15}$. 
Quanto à equipe de enfermagem, 95\% qualificaram 0 atendimento como ótimo ou bom, $25 \%$ afirmaram não ter conversado com algum integrante da equipe e $5 \%$ se disseram insatisfeitos com as informações prestadas. 0 tempo permitido para a visita foi citado por $29 \%$ dos entrevistados como insuficiente ${ }^{15}$.

Esta concepção dos familiares acerca da visita em UTI, na interface com o debate ora proposto, também foi abordada em outro estudo, no qual se observou, quanto às orientações, que 23 familiares (56\%) responderam ter existido esclarecimentos sobre a unidade, sua finalidade, normas e rotinas. Os profissionais mencionados como orientadores pelos familiares foram: psicólogo (11), assistente social (6), médico (1), recepcionista (1), quatro não disseram de quem receberam as orientações ${ }^{16}$. Um aspecto interessante na análise da problemática da humanização nesta investigação foi 0 reconhecimento do enfermeiro na UTI. Verificou-se que 70,7\% dos familiares não sabiam quem era o enfermeiro, e destes, $76 \%$ disseram que gostariam de conhecer o enfermeiro. Além disso, a presença do enfermeiro durante a visita foi destacada como um desejo de $63 \%$ dos familiares ${ }^{16}$.

Com base no que foi exposto, discutem-se tais resultados tendo como eixo nor teador a $\mathrm{PNH}$, na qual uma das marcas e prioridades é que todos conheçam quem são os profissionais que cuidam da sua saúde. As unidades de saúde devem garantir as informações aos usuários, o acompanhamento de pessoas de sua rede social e os direitos do código dos usuários do SUS. Como diretriz para a implementação da PNH nos níveis de atenção, destaca-se a ampliação do diálogo entre os profissionais e a população.

Um dos elementos da PNH é o acolhimento como uma postura e prática para um SUS humanizado, favorecendo uma relação de confiança e compromisso entre as equipes e os serviços. 0 acolhimento deve ser entendido como "um modo de operar os processos de trabalho em saúde assumindo uma postura capaz de acolher, escutar, observar e dar respostas adequadas aos usuários"17:21.

Partindo dessas premissas, defende-se o cumprimento do direito do cidadão expresso na Carta dos Direitos dos Usuários da Saúde de receber informações claras sobre seu estado de saúde, a qual deve ser extensiva aos familiares. É preciso valorizar a presença do familiar na unidade, em especial no momento da internação, pois resgata-se a ideia de individualidade do ser, trazendo aspectos positivos na recuperação da pessoa enferma, além de contribuir com informações que ajudarão a equipe de enfermagem a articular um plano de cuidados que seja compatível com seus valores e expectativas.

No entanto, para que essa contribuição ocorra de forma significativa torna-se fundamental o acesso dos familiares às informações sobre as rotinas do setor, para que estes compreendam o ambiente em que se encontram, permitindo aflorar o sentimento de acolhimento, respeito, e também de cuidado. Assim, a permanência do familiar na unidade é prioritária para que possa ser estabelecida uma relação terapêutica do profissional com os usuários e seus familiares ${ }^{14}$. Sobre a infraestrutura para atender o familiar, evidenciou-se, nos resultados desta pesquisa, que o que se tem vai de encontro aos preceitos da PNH no que tange à ambiência e ao protagonismo dos sujeitos partícipes do cuidado, devendo-se, pois, ser objeto de debate entre gestores, profissionais e usuários do sistema.

$\mathrm{Na}$ especificidade da assistência de enfermagem, refletir sobre a (in)visibilidade dos profissionais de enfermagem diante dos familiares é mister. Isso porque a equipe de enfermagem está em tempo integral prestando cuidados intensivos ao usuário, e em grande parte corresponde ao maior quantitativo de profissionais neste setor. Nesta perspectiva, é deveras relevante salientar que um dos conceitos fundamentais para o cuidado de enfermagem humanizado é a relação interpessoal, que deve se fazer presente independente do cenário de atuação ${ }^{16}$. Esta toma como base a comunicação, por meio da qual o profissional é visto como o eixo central das orientações, atento a todo o contexto que envolve o usuário, incluindo o familiar, percebendo, assim, o comportamento e reação deste diante da situação de ter um ente hospitalizado.

A equipe como foco de atenção humanizada na terapia intensiva

As dificuldades enfrentadas pela equipe de enfermagem no âmbito da assistência prestada por esses profissionais na $\mathrm{Tl}$, e que guardam nexos com a discussão em torno da humanização, foram aglutinadas neste eixo temático que se propõe a exemplificar como os enfermeiros lidam com tal questão, e que implicações estas situações trazem na prática de cuidar. Dentre os fatores dificultadores está a interface do enfermeiro com os outros profissionais que integram a equipe de saúde. Verifica-se que o médico ocupa posição central neste relacionamento com a equipe, o qual é demarcado nos discursos por uma não linearidade, de onde emergem possíveis conflitos que podem dificultar o exercício do profissional, retraí-lo e impactar nos seus modos de agir.

O que me dificulta é a falta de interação profissional, eu acho que as outras profissões não têm a mesma; não é que não tenham a mesma, as outras profissões tem certo afastamento da enfermagem como um todo. Essa falta de multidisciplinaridade, porque a multidisciplinaridade é importante, mas aqui a gente não vê com frequência, você vê os médicos fazendo suas visitas, suas prescrições e entrando para o seu quarto, os fisioterapeutas fazendo seus atendimentos e entrando para o seu quarto (Enf. 7).

Dificulta também o fato de o trabalho, às vezes, não ser multidisciplinar, o médico está trabalhando, 
mas ele não pensa no trabalho da enfermagem. Algumas condutas que tomam às vezes não são repassadas ou explicadas, a comunicação em alguns momentos dificulta meu trabalho (Enf. 9).

Os enfermeiros ressentem-se da não integração entre os profissionais na assistência, na decisão sobre as ações. Essa influência se materializa também na existência de determinantes externos que impactam nas práticas assistenciais da $\mathrm{Tl}$, como é o caso das condições de trabalho, que toma a atenção e concorre para uma sobrecarga do enfermeiro. Problemas relacionados à estrutura institucional, à exemplo do quantitativo de membros da equipe de enfermagem em comparação ao número de leitos no CTI, disponibilidade de material, bem como no que tange às questões salariais e a necessidade de outras atividades rentáveis, que denotam ter fortes reflexos no nível de desgaste, cansaço e talvez motivação dos enfermeiros.

Fala-se muito em humanização, humanização, humanização, só que eu não vejo como você humanizar um profissional se antes não existiu ninguém para humanizar a vida desse profissional. Eu acho que há necessidade de buscarmos qualidade de vida; e aí no que se diz respeito à qualidade de vida, nós focamos na parte financeira, e isso implica carga de trabalho maior que a esperada ou desejada. E o nosso dia-a-dia, nossa rotina influencia negativamente no cuidado. Não acho que as enfermeiras do CTI são desumanas, mas acho que vivemos em um mundo desumano (Enf. 2).

Preocupa, eu acho que a sobrecarga de trabalho é prejudicial, a gente tem um nível de trabalho, não só em terapia intensiva mas como um todo, a gente tem um nivel de trabalho muito estressante. Numa terapia intensiva esse nivel de trabalho exige muito da gente fisicamente, você vê profissionais com mais tempo de serviço terem problemas físicos mesmo, ortopédicos, musculares. Acho que essa busca incessante de condição financeira, de ascensão, faz a gente acumular muitos empregos. Quanto mais emprego o enfermeiro tem, mais distante ele é dos pacientes (Enf. 7).

No serviço público que tem uma estrutura, que está aquém do que deveria ter, que poderia ter. Outra coisa também em relação a essa questão estrutural, número de vagas, éa questão do número de pessoal, querendo ou não, o serviço de maior complexidade, ele exige um número maior de pessoas lidando diretamente com a assistência. Isso certamente traz prejuízo tanto do ponto de vista da assistência, quanto para o próprio profissional, ele fica mais sobrecarregado, mais cansado (Enf. 21).

A carga negativa ligada à atuação na $\mathrm{TI}$, enfatizada nas unidades de registros, guarda relações com as características do trabalho neste cenário. Esta negatividade é impressa à fala elaborada sobre a prática, principalmente quando tratam do envolvimento emocional ou do sofrimento que emerge das histórias dos usuários que cuidam, revelando esta dimensão do seu fazer.

Acho que existe uma carga muito negativa aqui dentro, você trabalha, você não ouve coisas boas, você chega um familiar aqui, o familiar está chorando, está te despejando mais angústias, em cima de você, e quem escuta é o enfermeiro, enfermagem, não é o médico, o fisioterapeuta (...) esse sofrimento diário, eu acho que com o decorrer dos anos, isso vai te consumindo (...) você trabalha sob pressão, você precisa estar sempre atento, sempre atento, sempre atento, então essas coisas, essa carga pesada, esse trabalho sob tensão 100\% do dia ninguém aguenta (Enf. 6).

Estes resultados abordam outra face da humanização no cotidiano do cuidar, geralmente pouco discutida quando se trata de analisar a prática dos enfermeiros. 0 excesso de trabalho e o lidar com a complexidade implicada nesse tipo de assistência, mormente quanto ao conhecimento científico envolvido, acarreta sobrecarga física e psíquica ao profissional, repercutindo em suas ações de cuidar, geralmente mecanicistas $^{16}$. Em alguns momentos, pode-se observar que a condição de saúde do usuário faz com que a equipe de enfermagem crie um mecanismo de defesa de distanciamento, adquirindo atitudes frias, fato este corroborado pela literatura ${ }^{14}$.

Vê-se, portanto, que a humanização envolve também o cuidado à equipe de enfermagem. É necessário criar meios para que o profissional enfrente as tensões e sentimentos, não somente os dele, mas os do usuário que ele cuida e do familiar.

Tal fato é priorizado pela PNH quando destaca a co-participação de todos os sujeitos no processo de saúde e inclui no cuidado também os profissionais. Uma das medidas que podem ser adotadas pelos profissionais de enfermagem que trabalham nessa unidade e enfrentam grande tensão e estresse é a possibilidade de criação de espaços onde se tenha a oportunidade para trabalhar conflitos, lidar com a profissão e refletir sobre as ações assistenciais ao usuário ${ }^{19}$, contribuindo para a melhoria dos serviços prestados no ambiente hospitalar.

0 enfoque do trabalho de grupo em articulação com a noção de humanização encontra respaldo na PNH, cuja ideia é criar um espaço para reflexão no próprio ambiente de trabalho, 
onde todos os trabalhadores possam estabelecer práticas pautadas pelo diálogo, refletindo sobre os principais conflitos que ocorrem no cotidiano, propondo melhorias através do estabelecimento de negociações.

Estratégias como estas fazem com que os profissionais lidem melhor com as tensões em seu ambiente de trabalho, garantindo assim a saúde não somente dos usuários, mas dos profissionais que têm atendidas as suas necessidades. Sabe-se que o sofrimento causado aos profissionais pelo trabalho é um fator desumanizante, repercutindo-se na qualidade da assistência prestada em saúde, no caso, da TI.

\section{CONSIDERAÇÕES FINAIS}

Grande parte dos conteúdos expressos nos discursos dos enfermeiros sobre a prática aponta que dispositivos da PNH, como a visita aberta, a ambiência, o acolhimento, a integração da equipe multiprofissional, as oficinas, os grupos de trabalho de humanização, não são implementados na UTI que serviu de cenário a esta pesquisa. Esta situação pode retratar a realidade de muitas outras UTI existentes no Brasil. E isto aponta para a necessidade de se expandir esta pesquisa na busca da ampliação de seus resultados.

Destaca-se a necessidade do respeito aos preceitos da PNH, bem como aos do SUS acerca da autonomia e participação dos profissionais, usuários e familiares no contexto assistencial $\mathrm{da} \mathrm{Tl}$ ao que remete ao cuidado humanizado de enfermagem. Esse papel dar-se-á valorizando-se cada partícipe no processo de trabalho e seus valores.

No interesse da problemática posta em discussão, tornase relevante aprofundar a dimensão de análise deste debate, sobretudo quando pensado à luz da PNH. Esta afirmação pautase nos resultados desta investigação, na medida em que indicam que existem outros fatores que requerem atenção quando se pensa sobre a humanização.

Os modelos em torno dos quais se organizam os cuidados de enfermagem priorizam as atividades fragmentadas, pautadas na doença e na cura, terminam por influenciar nas elaborações feitas pelos profissionais sobre sua prática, impactando nos seus modos de agir, caracterizados pela valorização de atividades burocráticas e dos dados estritamente clínicos do usuário adoecido.

Repensar a infraestrutura do cuidado é imprescindível, em termos de recursos humanos, principalmente fornecendo condições para o exercício profissional adequado e subsidiando um cuidado seguro, ético e de qualidade.

Quanto às tecnologias no cuidado, reconhece-se seu papel fundamental no contexto da TI como um dos recursos que auxiliam na recuperação do doente e que trazem enormes desafios aos profissionais, já que se trata de um instrumental que medeia racionalidade e subjetividade, suscitando atenção e preparo dos enfermeiros. Porém, outras variáveis estão imbricadas neste processo de assistir, as quais merecem um olhar mais atento em vista da melhoria do atendimento aos usuários, a partir da efetivação na prática da PNH, deslocando de lugar esta excessiva preocupação com as tecnologias.

Para tal, sugere-se investir em educação permanente dos profissionais de TI visando compreender como tal realidade acaba interferindo e criando representações acerca da humanização, as quais podem estar se apresentando como obstáculos para a implementação da PNH, principalmente no momento do diálogo entre profissionais e usuários e/ou familiares. Logo, essas estratégias podem contribuir para que se efetivem, no campo assistencial, os preceitos da PNH, em respeito à cidadania de todos.

\section{REFERÊNCIAS}

1. Silva MJP, Araújo MMT, Puggina ACG. Humanização em Unidades de Terapia Intensiva. In: Padilha KG, Vattimo MFF, Silva SC, Kimura M, organizadores. Enfermagem em UTI: cuidando do paciente critico. Barueri: Manole; 2010. p. 1324-366.

2. Silva GF, Sanches PG, Carvalho MDB. Refletindo sobre o cuidado de enfermagem em unidade de terapia intensiva. REME: rev min enferm. $2007 \mathrm{jan} / \mathrm{mar} ; 11(1)$ : 94-98.

3. Bermejo JC. Humanizar a saúde: cuidado, relações e valores. Rio de Janeiro: Vozes; 2008.

4. Silva RCL, Porto IS, Figueiredo NMA. Reflexões acerca da assistência de enfermagem e o discurso de humanização em terapia intensiva. Esc Anna Nery. 2008 mar; 12(1): 156-59.

5. Silva RCL, Figueiredo NMA, Porto IS, Jacintho TDE, Oliveira S, Vieira C. Humanização em terapia intensiva: analisando a idéia de desumanização na perspectiva ético-legal do cuidado de enfermagem. Rev Enferm UFPE. [on-line]. 2009 jul/set; [citado 2012 abr 14]; 3(3): [aprox 9 telas]. Disponível em: http://www.ufpe.br/revistaenfermagem/index.php/revista/ article/viewFile/175/175

6. Merhy EE. Em busca de ferramentas analisadoras das tecnologias em saúde: a informação e o dia a dia de um serviço, interrogando e gerindo trabalho em saúde. In: Merhy EE, Onoko R, organizadores. Agir em saúde: um desafio para o público. São Paulo: Hucitec; 2002. p. 113-50

7- Silva RCL, Kaczmarkiewicz CC, Cunha JJSA, Meira IC, Figueiredo NMA, Porto IS. 0 significado da tecnologia no pós-operatório imediato de cirurgia cardíaca. Rev Bras Cardiol. 2009 jul; 22(4): 210-18.

8. Barra DCC, Justina AD, Bernardes JFL, Vespoli F, Rebouças U, Cadete MMM. Processo de humanização e a tecnologia para o paciente internado em uma unidade de terapia intensiva. REME: rev min enferm. 2005 out/ dez; 9(4): 344-50. 
9. Ministério da Saúde (BR). HumanizaSUS. Política Nacional de Humanização. A humanização como eixo norteador das práticas de atenção e gestão em todas as instâncias do SUS. Brasília(DF); 2004.

10.Bardin L. Análise de conteúdo. Lisboa: Ed 70; 2009.

11. Pina RZ, Lapchinsk LF, Pupulim JSL. Percepção de pacientes sobre o período de internação em unidade de terapia intensiva. Cienc Cuid Saude. 2008 out/dez; 7(4): 503-08

12. Silva RC, Ferreira MA. Representações sociais dos enfermeiros sobre a tecnologia no ambiente de terapia intensiva. Texto \& Contexto Enferm. $2009 \mathrm{jul} / \mathrm{set} ; 18(3):$ 489-97.

13. Cunha PJ, Zagonel IPS. As relações interpessoais nas ações de cuidar em ambiente tecnológico hospitalar. Acta Paul Enferm. 2008;21(3): 412 19.

14. Silveira RS, Lunardi VL, Wilson Filho DL, Oliveira AMN. Uma tentativa de humanizar a relação da equipe de enfermagem com a família de pacientes internados na UTI. Texto \& Contexto Enferm. 2005; 14( n.esp): 125-30.

15. Wallau RA, Guimarães HP, Falcão LFR, Lopes RD, Leal PHR, Senna APR, et al. Qualidade e humanização do atendimento em medicina intensiva. Qual a visão dos familiares? Rev Bras Ter Intensiva. 2006 jan/mar; 18(1): 45-51.

16. Beccaria LM, Ribeiro R, Souza GL, Scarpetti N, Contrin LM, Pereira RAM, et al. Visita em unidades de terapia intensiva: concepção dos familiares quanto à humanização do atendimento. Arq Cienc Saude. 2008 abr/jun; 15(2): 65-9.

17. Ministério da Saúde (BR). Política Nacional de Humanização da Atenção e Gestão do SUS. Acolhimento e classificação de risco nos serviços de urgência. Brasilia(DF); 2009.

18. Chernicharo IM, Silva FD, Ferreira MA. Humanização no cuidado de enfermagem nas concepções de profissionais de enfermagem. Esc Anna Nery. 2011 dez; 15(4): 686-93.

19. Ministério da Saúde (BR). Humaniza SUS: Gestão participativa e cogestão. Brasília(DF); 2004. 